\title{
THE INJURED HOMO OBESUS: DOES TRAUMA AFFECT THIS CREATURE DIFFERENTLY TO WILD TYPE HOMO SAPIENS?
}

\section{Stephen R. Manning}

Department of Medical Education, University of Birmingham, Sandwell General Hospital, Lyndon, West Bromwich, UK

\begin{abstract}
Homo obesus (Man the obese) is known to have differences in cardiometabolic profile compared to wild type $H$. sapiens (Man the wise). To explore the differences in the affect of trauma upon $H$. obesus a thorough literature search was performed. In this review evidence is brought together to show the differences in injury patterns seen between $H$. obesus and wild type $H$. sapiens, the differences in outcome following trauma and how the altered adipokine and osteokine profile of $H$. obesus influences his bone structure. We see that the obese state is a risk factor for both increasing severity of limb trauma and increased mortality, critical care length of stay and death following blunt trauma. This risk may be influenced by the abnormal adipokine profile. In particular the roles of adiponectin, leptin, PPARy, TNF- $\alpha$ and IL- 6 are considered. The effect of chronic inflammatory insult prior to trauma in the obese adult is considered and its potential influence over the outcome is debated. Following major blunt trauma the robust appearing physique of $H$. obesus shows it's fragility with an increased risk of death and longer hospital stay.
\end{abstract}

Adipobiology 2010; 2:57-66

Key words: adipokines, bone mineral density, obesity, osteokines, PPARy, trauma

Received 10 December 2010, accepted 21 December 2010.

Correspondence: Dr Stephen R. Manning, 30 Pennyroyal Close, Tamebridge, Walsall, West Midlands, WS5 4SJ, UK.

Tel.: 0044 (0)1922 641727, E-mail: stephen.manning@doctors.org.uk

\section{Introduction}

The concept of Homo obesus was first introduced in 2007 (1). It describes a phenotypic variant of $H$. sapiens characterized by obesity - probably - due to deficiency in metabotrophic factors, such as adiponectin, nerve growth factor (NGF), brain-derived neurotrophic factor (BDNF), interleukin (IL-10), responsible for the homeostasis of glucose and lipids metabolism and of cardiovascular and immune system. $H$. obesus also has abnormal inflammatory activity and is at risk of metabolic diseases such as type 2 diabetes and atherosclerosis. As $H$. obesus ages and develops type 2 diabetes, he/she may begin to dement and a common pathway may lead onto Alzheimer's disease (2).

Homo obesus is clearly not a healthy phenotype and through his own metabolism may progress to ill health. To observe $H$. obesus we see a large solid frame, a robust appearing structure capable of independent locomotion and having the physical strength to carry this bulk from place to place. 
It may not be as fast as wild type $H$. sapiens but the effort and strength shown are greater. Despite these outward appearances, H. obesus may be more fragile than we think and may be at higher risk of injury than H. sapiens. However, as we shall see, nothing in nature is clear and $H$. obesus may be at higher risk of injury or may have some protection from injury.

\section{Risks of injury to Homo obesus}

Most children do not sustain a fracture during their childhood. Of those fractures that are sustained some $66 \%$ occur in children who have already had one fracture during their short lives. Most of these fractures will be treated as outpatients and will have occurred during play or sport rather than being due to severe trauma. Commonly, fractures occur at times of peak bone turnover such as early puberty. It has been suggested that risk factors include poor nutrition, lack of physical exercise, and obesity. In apparently normal children with fractures bone mineral density, bone accrual and bone size are smaller than those without fractures $(3,4)$. Obese children with a history of fractures have been shown to have a lower total bone mineral density (BMD) and a lower bone mineral content for lean mass $(5,6)$. It is suggested that fat mass substantially inhibits bone accrual in children with previous fractures (6).

The overall risk of injury to the obese child may not be higher than the non obese population but certain regions are more commonly injured in certain circumstances. In motor vehicle collisions, occupants aged 9-15 who are overweight have been seen to be at higher risk of lower and upper limb injuries than their normal weight counterparts. This may be due to a difference in biomechanical forces applied to the larger frame of the overweight child involved in a vehicle collision (7). The extremity injury acquired is more likely to require operative intervention in the overweight child and the child is at higher risk of complications such as venous thromboembolic disease and decubitus ulceration than the normal child (8). Outside of the higher energy trauma setting; based upon bone mineral density measurements, obese boys have been shown to be at higher risk of forearm fracture than non-obese, even when controlling for lower fall heights and softer impact surfaces (9). When the adiposity is formally measured in patients with distal forearm fractures, it has been shown that increasing levels of adiposity and decreasing levels of lean mass are associated with fractures (10).

As $H$. obesus matures, a clear association between increasing BMI and increasing risk of injury has been shown (11). Mathematical modeling of the posture of H. obesus has found that the altered centre of gravity, compared to wild type H. sapiens, can lead to a higher risk of falling (12). This is something that $H$. obesus can be aware of. Fear of falling is an important prob- lem in mobility of higher functioning older patients and is associated with reduced levels of physical activity (13). Decreased weight bearing activity is known to be associated with a decrease in bone mineral density in the elderly (14) and the young (15). A range of social and psychological risk factors are positively associated with fear of falling and obesity is one proven risk factor which can be important in removing fear of falling and encouraging load bearing exercise (16).

Fear of falling does not affect all people. What effects upon the bone are seen in the more mobile H. obesus? Clearly, if H. obesus is to be mobile then the skeletal system must be strong enough to carry the increased weight. We have seen that load bearing exercise increases bone mineral density. It has been found that severe obesity $\left(\mathrm{BMI}>35 \mathrm{~kg} / \mathrm{m}^{2}\right)$ increases volumetric bone mineral density and cortical bone mineral content but lower cortical BMD (17). Much attention is given to low BMD and post menopausal women are the group most often investigated with bone mineral density scanning. What of high BMD? A large study of over 16,000 women has shown that high BMD is closely associated with high BMI (18). It is not only the fat content that contributes to increased bone mineral density, lean mass has been shown to be an important contributor too (19). This relationship has not been observed in non-caucasion women. It has been found that African American women with increasing BMI have a slight but significant decrease in bone mineral density (20). Most commonly it is the load bearing bones of the lumbar spine and femoral neck that are scanned for bone mineral density. Outside of these load bearing areas, we could expect the increased mechanical loading effect of $H$. obesus to be eliminated as a factor influencing bone mineral density. Prior to menopause obesity does not predict bone mineral density in the distal forearm (21). Increased bone mineral density related to the obese state appears to be transient, lasting as long as the obese state lasts. It has been seen, in a relatively small randomized controlled trial, that weight loss even when combined with exercise in obese adults results in a decrease in BMD (22).

If increased BMI is related to increased bone mineral density in some groups, could obesity have a protective effect against osteoporosis? The literature is sparse and contradictory. Based upon lumbar vertebral bone mineral density, an association has been seen between lower BMD and higher BMI (23). Increased BMI has shown a protective effect against hip fracture but a higher risk of humerus fracture, whereas low BMI has appeared as a risk factor for hip fracture and not for humerus fracture (24). We can consider possible reasoning for this. A higher BMI will increase load bearing through the femoral neck and thus increase cortical bone mineral density. The result: a stronger and more robust bone able to withstand higher impact forces. 
A lower BMI does not confer this load bearing advantage. The humerus however, is not a load bearing bone, it may be involved in levering the frame of $H$. obesus into a standing position but prolonged load bearing is not a regular occurrence, thus BMD is not increased in the same way as the femoral neck. The result: a substantial impact to the humerus caused by Homo obesus falling is enough to break the humerus. Another recent study has demonstrated a protective effect of higher BMI towards femoral neck fractures but not towards upper extremity or less well padded lower extremity fracture sites (25).

Could we hypothesise that normal BMD for wild type $H$. sapiens is abnormally low for $H$. obesus? Perhaps we can. There is evidence that most obese woman with low energy trauma fractures have what is regarded as normal BMD for the general population of their age. In this particular study, the prevalence of obesity and morbid obesity was surprisingly high (26). Men show similar findings. Obesity is not uncommon in older men and when BMD is held constant, obesity is associated with increased fracture risk (27). Amongst those women who do have osteoporosis, both increasing weight and increased BMI have been shown to be risk factors for vertebral fractures (28).

Homo obesus is at increased risk of developing type 2 diabetes and related cardiometabolic diseases (1). Does this have any influence upon bone mineral density or fractures? It was found that patients with non insulin dependant diabetes had a higher bone mineral density than those with normal glucose tolerance, this difference could not be explained by obesity or several other factors. It was also seen that women in this group had a lower incidence of non-vertebral fractures while in men there was no difference in fracture frequency (29). Again as time passes so the literature evolves and by 2001 a larger prospective study of postmenopausal women found that having or developing diabetes put women at higher risk of hip fracture than non-diabetic women (30). A large historical cohort study performed in 2008 also found that diabetic patients had a higher risk of fractures overall and hip fractures specifically, compared to non-diabetics (31). The incidence of vertebral fractures appears to be increased in type 2 diabetes in both men and women. In men, despite having apparently normal bone mineral density, the combination of hyperglycaemia and obesity has been identified as a significant risk factor for vertebral fracture in diabetic men (32).

The metabolic syndrome has been inconsistently identified as a risk factor for osteoporotic fractures but was also associated with a higher BMD (33) and also associated with lower BMD and lower fracture risk (34).

Bone mineral density is but one contributor towards bone strength. It has also been seen that structural geometry of the bone influences bone strength and together alterations in geom- etry and decrease in mineral density account for a significant change in bone strength (35). Recently it has been seen that although obesity may have some protective effect in adults against fractures, in children it seems to be a risk factor for fractures. Bone characteristics of mice were assessed after a high fat diet and it was found the bone quantity and bone quality were important determinants of bone strength. Thus, the obese patient may have higher mineral content and bone turnover but the quality of the bone maybe reduced in such a way that it loses some mechanical strength $(36,37)$.

See Editorial on page 73-75

\section{How do injury patterns in Homo obesus differ?}

Obese children appear to be more likely to sustain a lower extremity injury then their non-obese counterparts $(7,8,38)$. Interestingly, these children seem less likely to suffer head or facial injuries. Those that do require operative management of femoral fractures are at higher risk of complications (39). In the adult population, following motor vehicle collisions, obese patients have been found to have significantly more severe distal femur fractures than non-obese patients (40).

Obesity is associated with a significantly higher likelihood of an ankle fracture being more severe and requiring manipulation or operative fixation $(41,42)$. As well as being a risk factor for needing manipulation of the fractured ankle, obese patients have a higher risk of this manipulation failing or of internal fixation failure needing revision surgery (43). In the upper limb elbow fractures requiring surgery are associated with obesity (42) as are humeral fractures (24) and of those who do sustain humeral fractures, obesity is a risk factor for non-union (44).

Outside of the skeletal system head injuries have been looked at in obese and non obese adults involved in frontal motor vehicle collisions. An Italian study of close to 6,000 patients found that obese passengers were more likely to sustain a more severe head trauma than non obese passengers following collision (45). It had been hypothesized that obesity in patients with head injuries would potentially lead to a poorer outcome. However an American study did not support this hypothesis. Obese patients with head injury did not have a higher mortality or morbidity. Instead the increases in mortality and morbidity could all be accounted for by increasing age, lower admission blood pressure and concurrent chest injury (46).

Does obesity confer any protective advantages against injury? A protective affect of obesity has been suggested when considering pelvic fractures. An American study looking at side impact motor vehicle collisions identified lower BMI as a risk factor for 
pelvic fractures, where as obesity appears to show a protective affect (47). In children it has been found that obesity is associated with a lower risk of intracranial and intraabdominal injuries after trauma (8). Of those obese adults who do sustain a pelvic ring injury, should it need operative fixation, then BMI correlates with an increase risk of complication and re-operation $(48,49)$.

It seems then, that $H$. obesus can be at a higher risk of sustaining a more severe and complicated lower or upper limb injury than his non obese counterpart. There does not appear to be any difference in head injuries and obesity may offer some protection against pelvic injury. However, should surgery be needed for the pelvic injury then the likliehood of complications is higher in H. obesus.

\section{Outcome for the critically injured Homo obesus}

Should the trauma sustained be severe enough, $H$. obesus may enter the critical care environment. In this highly specialized area of the hospital we find the sickest patients. How does the obese state influence the critically injured $H$. obesus?

Although some literature exists suggesting that obesity significantly increases both morbidity and mortality in the obese critically ill trauma patient (50) the weight of published literature suggests that obesity itself does not increase mortality in the critical care environment (51-57). Obesity may influence length of stay in the critical care unit $(51,57,58)$ and also may influence prolonged duration of mechanical ventilation (51).

Outside of the specific group of patients found in critical care environments, obesity may have some influence on overall survival of the injured $H$. obesus. Injury may be so severe that death occurs before reaching the critical care environment or conditions may alter during surgery or on a normal ward resulting in death before reaching the critical care unit. Again, literature exists to support either the hypothesis of increased mortality associated with obesity (59) or the hypothesis that obesity does not influence mortality $(60,61)$.

When grouped on mechanism of injury those who have sustained blunt trauma, as opposed to penetrating trauma, a study over 1,000 such patients found a few differences between obese and non-obese subjects. The obese were more likely to have lower extremity injuries, chest injuries, increased lengths of hospital stay, higher complication rates and longer lengths of ventilation than the non-obese. Also, in this group, obesity was identified as a risk factor for mortality (62). A case control study has again identified obesity as an independent predictor of mortality following blunt trauma (63). This increased mortality confirmed a finding of some years earlier of increased mortality in blunt trauma patients that were severely over weight despite advanc- es in trauma care in the last 15 years (64). A further study that found increased mortality among morbidly obese trauma patients was able to show that mortality increased in the morbidly obese when injury progressed from a single organ system failure to a multi-organ system failure (65).

\section{Adipobiology and the skeleton of Homo obesus}

Adipose tissue plays a central role in energy homeostasis and in recent times has become recognized not as an inert storage for triglycerides but as an active endocrine organ (1). Adipoproteomic analyses have identified more than $100 \mathrm{mul}$ tifunctional secretory proteins collectively termed adipokines (66). Through endocrine and paracrine pathway they influence metabolic, vascular, inflammatory and cognitive processes. Adipokines include leptin, adiponectin, cytokines such as tumor necrosis factor-alpha (TNF- $\alpha$ ), IL-6, IL-10, IL-18, IL-32, visfatin, apelin, neuropeptides and neurotrophins (NGF, BDNF) amongst others; obese individuals have higher levels of pro-inflammatory adipokines and lower levels of the metabotrophins adiponectin, NGF and BDNF $(1,66)$.

Adipose tissue and bone are linked by several biochemical pathways which ultimately result in a skeleton of appropriate structure and strength to support the soft tissue mass and provide locomotion for the individual. Recently, bone-derived secretory proteins collectively designated osteokines were recognized (67); via endocrine pathway, they exert control on various extrabone processes including glucose and lipid metabolism (Gumpeny and Gumpeny in this volume of Adipobiology, also see 68$)$.

\section{How do the well documented adipokines influence bone metabolism?}

Leptin

Leptin is produced mainly by the adipocytes (66) but also in low levels by gastric fundal epithelium, intestine, placenta, skeletal muscle, mammary epithelium, brain, and bone cells. Leptin levels are related to energy stores such that they are increased in obesity and decreased in fasting states. With respect to bone, leptin has been seen to cause and increase in bone formation, indeed a positive correlation is seen between serum leptin levels and BMD (69). Acting upon the central nervous system via the JAK-STAT pathway, leptin has influence upon bone and cartilage growth. Leptin also has direct effects upon osteocytes that express leptin receptors leading to osteoblast proliferation and maturation, osteoclast development, and chondrocyte activity $(70,71)$. Leptin influences the GnRH and GHRH pathways at the pituiatary and hypothalamic levels. Leptin has been seen to have inhibitory actions on somatostatin relaease and increase in $\mathrm{GH}$ 
release. GH release leads to the release of IGF-1 which in turn stimulates the growing pates of bones. Via its influence on the GnRH pathway, leptin influences pubertal bone growth. Obese children are often taller prior to puberty but have earlier onset of puberty. Leptin levels have been seen to rise prior to puberty by $50 \%$ suggesting that leptin may influence the onset of puberty by increasing $\mathrm{GnRH}$ secretion. As well as acting via central effects, leptin receptors have been found in growth plates, implying that leptin can act peripherally to increase bone growth (72).Those who have a growth hormone deficiency have short stature and reduced bone mineral density but increased adiposity and leptin levels. Central leptin administration has been seen to impair trabecular bone formation while peripheral leptin has been seen to enhance cortical mineral accrual. These conflicting results may suggest that an important balance between central and peripheral leptin effects final bone strength and leptin has differing influences upon different parts of the bone microstructure (37).

\section{Adiponectin}

Adiponectin is the most abundant protein secreted by adipose tissue and has a higher concentration in the circulation than other secreted cytokines. Unlike leptin, adiponectin levels are decreased in the obese state, its levels increase during weight loss. Adiponectin has been shown to have a negative effect upon both BMD and bone mineral content (73). It has been shown in vitro that adiponectin concentrations may alter bone mineral accrual by modulating insulin action upon bone. Adiponectin levels inversely correlate with adiposity, therefore it is possible that the obese state removes negative influence upon bone mineral accrual and thus leads to a higher BMD (73). The higher BMD seen in type 2 diabetes is associated with higher levels of circulating insulin.

\section{PPAR gamma}

Perioxisome proliferator-activated receptor gamma (PPAR $\gamma)$ is one of three nuclear receptors of the PPAR class, that is widely expressed but found predominantly in white adipose tissue. Several classes of ligands for PPAR $\gamma$ have been described and include poluyunsaturated fatty acids (e.g. arachidonic acid), prostaglandin like compounds, oxidized lipids and the pharmacological agents, the thiazolidine compounds $(74,75)$. It has been shown that women with osteoporosis have and increased accumulation of bone marrow adipocytes, as seen on iliac crest biopsies $(76,77)$. Both osteoblasts and adipocytes derive from a common origin, the mesenchymal stem cells. In mice, it has been seen that an increase in marrow adipocytes is correlated with an increase in expression of PPAR $\gamma 2$ and it has also been seen that PPAR $\gamma 2$ expression can direct preosteoblast cell lines to become adipocytes rather than osteoblasts (78,79). Aging heterozygote PPAR $\gamma$ knockout mice have been seen to have an increased number of osteoblasts and bone formation along with a lower number of marrow adipocytes when compared to aging wild type controls (80). Senesence accelerated strain mice have also been seen to have both increased levels of bone marrow adipocytes and mRNA ${ }^{\text {PPAR } 2}(81)$. The PPAR $\gamma$ has recently been shown to be phosphorylated by overfeeding mice. Although this does not alter the adipogenic capacity of PPAR $\gamma$, it has led to dysregulation of other adipogenic genes including reduced expression of adiponectin (82). In humans it has been seen that adiponectin mRNA levels were positively associated with mRNA $^{\text {PPAR }}$ in obese and diabetic patients, leading to the suggestion that adiponectin could be regulated by PPAR $\gamma$ in man (83). PPAR $\gamma$ is also a receptor for the protein nocturin. This circadian protein has been shown to enhance PPAR $\gamma$ transcriptional activity while mice deficient in nocturin are protected from obesity and have lower levels of bone marrow adipocytes (84).

\section{Interleukin-6}

Interleukin- 6 has been shown to be produced by adipose tissue, accounting for around 1/3 of the total IL- 6 produced without active inflammatory processes. In the obese, higher base line levels of IL-6 are seen when compared to non-obese (85-87). Through a stimulatory effect upon the osteoclast lineage, IL- 6 has become acknowledged as an osteoporotic factor (88).

\section{TNF-a}

Tumor necrosis factor-alpha has been shown to increase leptin production by adipocytes (89), and is associated with insulin resistance. Higher levels of TNF- $\alpha$ have been seen in both diabetics and obese $(87,90)$. It has also been seen that with weight loss, the circulating TNF- $a$ levels of obese subjects decrease and the degree of insulin resistance also falls. Therefore, with weight loss we could expect the the influence of TNF- $\alpha$ upon leptin expression to also decrease and thus the level of expressed leptin to decrease..$^{90}$ In the obese state then, it seems that higher leptin levels acting both centrally and peripherally can increase bone mineral density and bone formation rate but may impair trabecular bone structure. Lower adiponectin levels reduce the negative effect of adiponectin upon bone mineral accrual and lead to higher bone mineral density. The lower levels of adiponectin associated with obesity are further influenced by altered activity of PPAR $\gamma$ in the obese. Higher levels of IL-6 in the obese lead to stimulation of osteoclasts, whilst higher levels of TNF- $\alpha$ further stimulate leptin release. The balance between these processes will influence the rate of bone turnover and it is known that at periods of higher bone turnover fracture risk is increased (3). 
How does, if any, trauma to the body of $H$. obesus alter the adipokine profile? Following minimal trauma it has been shown that subcutaneous adipose tissue releases an increased amount of IL-6, up to 20 fold compared to the resting state while TNF- $\alpha$ increased by just over 50\% (91). A significant positive correlation between injury severity scoring and initial IL-6 concentrations has been seen and of those patients who develop multioragn failure after trauma, a significant difference between IL-6 and TNF- $\alpha$ levels is seen 1 day prior to death, compared to multiorgan failure survivors (92). IL-6 has been shown to be a potential predictive factor of the future development of multiorgan failure in the patient with hypovolaemic shock. ${ }^{93}$ After the controlled trauma of surgery, IL- 6 concentrations have been seen to increase from baseline levels and in the obese these base line and post operative levels have been seen to be related to abdominal adipose tissue content. Postoperative worsening of insulin resistance is associated with increasing plasma and adipose IL-6 levels (94). Similarly TNF levels have been seen to increase after hypovolaemic shock in rodent models. By resuscitating these models using resuscitation fluid containing ethyl pyruvate, TNF levels were seen to be suppressed and survival increased compared to models receiving standard resuscitation fluids only (95). Adiponectin has been shown to be low in trauma patients and critically ill patients due to an as yet unknown mechanism, suggesting that adiponectin may have a role in the inflammatory response to trauma $(96,97)$.

It has been postulated that the higher base line levels of proinflammatory adipokines seen in the obese patient may account for the excess mortality seen in the obese following critical injury. At first sight it appears to stand to reason that if levels of pro-inflammatory cytokines are initially high then, the adding on a further inflammatory response will inevitably worsen the inflammatory response and outcome. Recent evidence has not supported this view. It would seem that the magnitude of inflammatory response following trauma, for example, a 20 fold increase in IL-6, is so high that any base line alterations in inflammatory profile due to obesity are overwhelmed. Resolution of this inflammatory response in the period following injury may differ between patients of differing BMI but at present there is no published literature to support or refute this possibility $(98,99)$.

\section{Conclusion}

Homo obesus is a creature with bone structure different to that of wild type $H$. sapiens. The mineral content and density may be higher in $H$. obesus but the trabecular bone structure may not be as strong. The differing levels of adipokines circulating in $H$. obesus may lead to an increased bone turnover rate and unusual microstructure altering the density and strength of the bone. While the BMD may be increased when compared to wild type $H$. sapiens it may not have increased enough to offer a significant protective effect from the increased impact associated with a fall. In the weight bearing bones of mobile $H$. obesus an increase in strength is seen. Obese children are at higher risk of sustaining a lower limb fracture than non-obese children. Obese adults involved in motor vehicle collisions are at higher risk of sustaining more severe distal femur fractures. Obese adults who sustain ankle fractures are more likely to have more severe injuries and need manipulation or surgical fixation and this intervention has a higher rate of failure than in the non-obese. Obesity is a risk factor for upper limb fractures of the elbow, humerus and forearm. Obese adults are at higher risk of head injury in motor vehicle collisions. A protective effect is seen however against osteoporosis, based on current definitions for the population, and against sustaining pelvic ring fractures following motor vehicle collisions. In obese children a lower rate of head and abdominal injuries is seen. Should $H$. obesus require the facilities of the critical care unit it is likely that he will spend longer there than his non obese companion and may need a prolonged period of mechanical ventilation. Overall $H$. obesus suffering blunt trauma has a higher morality, and higher rates of extremity injury, chest injury and longer lengths of hospital stay. While the increased level of adiposity seen in $H$. obesus leads to higher base line levels of proinflammatory adipokines, compared to the non-obese (and in the case of adiponectin lower levels) this does not seem to be a suitable explanation for the excess mortality of $H$. obesus as, following blunt trauma, the magnitude of the trauma inflammatory response overwhelms the modest sub-clinical increase in these cytokines.

In short, $H$. obesus is at higher risk of injury than wild type $H$. sapiens. This risk may be influenced by the abnormal adipokine and/or osteokine profile. This injury is likely to be more severe especially if it is a limb injury. Following major blunt trauma the robust appearing physique of $H$. obesus shows it's fragility with an increased risk of death and longer hospital stay.

\section{Acknowledgements}

My wife Mrs Suzanne Manning has provided much encouragement and support in preparing this work.

\section{References}

1. Chaldakov GN, Fiore M, Tonchev AB, Dimitrov D, Pancheva $\mathrm{R}$, Rancic $\mathrm{G}$, et al. Homo obesus: a metabotrophin-deficient species. Pharmacology and nutrition insight. Curr Pharm Des 2007; 13: 2176-2179. 
2. Manning SR Diabetes and dementia: A common link or coincidental coexistence? Biomed Rev 2007; 18: 59-64.

3. Goulding A. Risk factors for fractures in normally active children and adolescents Med Sport Sci 2007; 51: 102-120.

4. Manias K, McCabe D, and Bishop N. Fractures and recurrent fractures in children; varying effects of environmental factors as well as bone size and mass. Bone 2006; 39: 652657.

5. Goulding A, Grant AM, Williams SM. Bone and body composition of children and adolescents with repeated forearm fractures. J Bone Miner Res 2005; 20:2090-2096

6. Dimitri P, Wales JK, Bishop N. Fat and bone in children: differential effects of obesity on bone size and mass according to fracture history. J Bone Miner Res 2010; 25: 527-536.

7. Pollack KM, Xie D, Arbogast KB, Durbin DR. Body mass index and injury risk among US children 9-15 years old in motor vehicle crashes. Inj Prev 2008; 14: 366-371.

8. Rana AR, Michalsky MP, Teich S, Groner JI, Caniano DA, Schuster DP. Childhood obesity: a risk factor for injuries observed at a level 1 trauma centre. J Pediatr Surg 2009; 44: 1601-1605.

9. Davidson PL, Goulding A, Chalmers DJ. Biomechanical analysis of arm fracture in obese boys. J Paediatr Child Helath 2003 39:(9) 657-64

10. Goulding A, Jones IE, Taylor RW, Williams SM, Manning PJ. Bone Mineral density and body composition in boys with distal forearm fractures: a dual energy x-ray absroptionmetry study. J Pediatr 2001; 139: 509-515.

11. Finkelstein EA, Chen H, Prabhu M, Trogdon JG, Corso PS. The relationship between obesity andinjuries among US Adults. Am J Health Promot 2007; 21: 460-468.

12. Corbeil P, Simoneau M, Rancourt D, Tremblay A, and Teasdale N. Increased risk for falling associated with obesity: mathematical modeling of postural control. IEEE Trans Neural Syst Rehabil Eng 2001; 9:126-136.

13. Bruce DG, Devine A, Prince RL. Recreational physical activity levels in healthy older women: the importance of fear of falling. J Am Geriatr Soc 2002; 50: 84-89.

14. Vuillemin A, Guillemin F, Jouanny P, Denis G, Jeandel C. Differential influence of physical activity on lumbar spine and femoral neck bone mineral density in the elderly population. J Gerontol A Biol Sci Med Sci 2001; 56:B248-253.

15. McKay H, Liu D, Egeli D, Boyd S, Burrows M. Physical activity positively predicts bone architecture and bone strength in adolescent males and females. Acta Paediatr 2010 Aug 24 (in print).

16. Austin N, Devine A, Dick I, Prince R, Bruce D. Fear of falling in older women: a longitudinal study of incidence, persist- ence, and predictors. J Am Geriatr Soc 2007; 55: 1598-1603.

17. Sukumar D, Schlussel Y, Riedt CS, Gordon C, Stahl T, Shapses SA. Obesity alters cortical and trabecular bone density and geometry in women. Osteoporosis Int 2010 June 9 (in print).

18. Morin S, Leslie WD. High bone mineral density is associated with high body mass index. Osteoporosis Int 2009; 20: 1267-1271.

19. Ho-Pharm LT, Nguyen LD, Lai TQ, Nguyen TV. Contributions of lean mass and fat mass to bone mineral density: a study in postmenopausal women. BMC Musculoskelet Disord 2010; 11:59.

20. Castro JP, Joseph LA, Shin JJ, Arora SK, Nicasio J, Shatzkes J, et al. Differential effect of obesity on bone mineral density in white, Hispanic and African American women: a cross sectional study. Nutr Metab (Lond) 2005; 2: 9.

21. Cox ML, Khan SA, Gau DW, Cox SA, and Hodkinson HM. Determinants of forearm bone density in premenopausal women: a study in one general practice. Br J Gen Pract 1991; 346: 194-196.

22. Villareal DT, Shah K, Banks MR, Sinacore DR, Klein S. Effect of weight loss and exercise therapy on bone metabolism and mass in obese older adults: a one year randomized controlled trial. J Clin Endocrinol Metab 2008; 93: 2181-2187.

23. Greco EA, Fonari R, Rossi F, Santiemma V, Prossomariti G, Annoscia C, et al.. Is obesity protective for osteoporosis? Evaluation of bone mineral density in individuals with high body mass index. Int J Clin Pract 2010; 64:817-820.

24. Gnudi S, Sitta E and Lisi L. Relationship of body mass index with main limb fragility fractures in post menopausal women. J Bone Miner Metab 2009; 27: 479-484.

25. Beck TJ, Petit MA, Wu G, LeBoff MS, Cauley JA, Chen Z. Does obesity really make the femur strobger? BMD geometry and fracture incidence in the womens health initiativeobservational study. J Bone Miner Res 2009; 24: 1369-1379.

26. Premaor MO, Pilbrow L, Tonki C, Parker RA, Compston J. Obesity and fractures in postmenopausal women. J Bone Miner Res 2010; 25: 292-297.

27. Nielson CM, Marshall LM, Adams AL, Leblanc ES, Cawthon PM, Ensrud K, et al. BMI and fracture risk in older men: the osteoporotic fractures in men (MrOS) Study J Bone Miner Res 2010 Sept 2 (in print).

28. Pirro M, Fabbriciani G, Leli C, Callarelli L, Manfredelli MR, Fioroni $\mathrm{C}$, et al. High weight or body mass index increase the risk of vertebral fractures in postmenopausal osteoporotic women. J Bone Miner Metab 2010; 28:88-93.

29. Van Deale PL, Stolk RP, Burger H, Algra D, Grobbee DE, Hofman A, et al. Bone mineral density in non-insulin de- 
pendant diabetes mellitus. The Rotterdam Study. Ann Int Med 1995; 122: 409-414.

30. Nicodemus KK, Folsom AR. Type 1 and type 2 diabetes and incident hip fractures in post menopausal women. Diabetes Care 200124 1192-7.

31. Melton LJ, Leibson CL, Achenbach SJ, Therneau TM, Khosla S. Fracture risk in type 2 diabetes: update of a population based study. J Bone Miner Res 2008; 23:1134-1142.

32. Kanazawa I, Yamaguchi T, Yamamoto M, Yamauchi M, Yano $\mathrm{S}$, Sugimoto T. Combination of obesity with hyperglycaemia is a risk factor for the presence of vertebral fractures in type 2 diabetic men. Calcif Tissue Int 2008; 83: 324-331.

33. Von Muhlen D, Safii S, Jassal Sk, Svartberg J, Barrett-Connor E. Associations between the metabolic syndrome and bone health in older men and women: the Rancho Bernardo study. Osteoporos Int 2007; 18: 1337-1344.

34. Szulc P, Varennes A, Delmas PD, Goudable J, Chapurlat R. Men with metabolic syndrome have lower bone mineral density but lower fracture risk - the MINOS study. J Bone Miner Res 2010; 25:1446-1454.

35. Donnelly E, Chen DX, Boskey AL, Baker SP, van der Meulen MC. Contribution of Mineral to Bone Structural Behavior and Tissue Mechanical Properties. Calcif Tissue Int. 2010 Aug 22 (in print).

36. Ionova-Martin SS, Do SH, Barth HD, Szadkowska M, Porter AE, Ager JW 3rd, et al. Reduced size-independent mechanical properties of cortical bone in high-fat diet-induced obesity. Bone 2010; 46:217-225.

37. Stevenson AE, Evans BAJ, Gevers EF, Elford C, McLeod RWJ, Perry MJ, et al. Does adiposity status influence femoral cortical strength in rodents models of growth hormone deficiency? Am J Physiol Endocrinol Metab 2008; 296: E147156.

38. Pomerantz WJ, Timm NL, Gittelman MA. Injury patterns in obese versus non-obese children presenting to a pediatric emergency department. Pediatrics 2010; 125: 681-685.

39. Leet AL, Pichard XP, Ain MC. Surgical treatment of femoral fractures in obese children: does excessive body weight increase the rate of complications? J Bone Joint Surg Am 2005; 87: 2609-2613.

40. Maheshwari R, Mack CD, Kaufman RP, Francis DO, Bulger EM, Nork SE, et al. Severity of injury and outcomes among obese trauma patients with fractures of the femur and tibia: a crash injury research and engineering network study. $J$ Orthop Trauma 2009; 23: 634-639.

41. Spaine LA, Bollen SR. The bigger they come...: the relationship between body mass index and severity of ankle fractures. Injury 1996; 27: 687-689.
42. Böstman OM. Body mass index of patients with elbow and ankle fractures requiring surgical treatment. J Trauma 1994 37: 62-65.

43. Böstman OM. Bodyweight related to loss of reduction of fractures of the distal tibia and ankle. J Bone Joint Surg 1995; 77 B: 101-103.

44. Green E, Lubahn JD, Evans J. Risk factors, treatment, and outcomes associated with nonunion of the midshaft humerus fracture J Surg Orthop Adv 2005 14: 64-72.

45. Tagliaferris F, Compagnone C, Yoganadan N, Gennarelli TA. Traumatic brain injury after frontal crashes: relationship with body mass index. J Trauma 2009; 66: 727-729.

46. Brown CV, Rhee P, Neville AL, Sangthong B, Salim A, Demetriades D. Obesity and traumatic brain injury. $J$ Trauma 2006; 61: 572-576.

47. Bansal V, Conroy C, Lee J, Schwartz A, Tominaga G, Coimbra R. Is bigger better? The effect of obesity on pelvic fractures after side impact motor vehicle crashes. J Trauma 2009; 67: 709-714.

48. Sems SA, Johnson M, Cole PA, Byrd CT, Templeman DC. Elevated body mass index increases early complications of surgical pelvic ring injuries. J Orthop Trauma 2010; 24: 309314

49. Lazar MA, Plocher EK, Egol KA. Obesity and its relationship with pelvic and lower extremity orthopaedic trauma. Am J Orthop 2010; 39: 175-182.

50. Bochicchio GN, Joshi M, Bochicchio K, Nehman S, Tracy JK, Scalea TM. Impact of obesity in the critically ill trauma patient: a prospective study. J Am Coll Surg 2006; 203: 533-538.

51. Akinussi ME, Pineda LA, El Solh AA. Effect of obesity on intensive care morbidity and mortality: a meta-analysis. Crit Care Med 2008; 36: 151-158.

52. Hogue GW, Stearns JD, Colantuoni E, Robinson KA, Stierer $\mathrm{T}$, Mitter N, et al. The impact of obesity on outcomes after critical illness: a meta-analysis. Intensive Care Med 2009; 35:1152-1170.

53. Lim SY, Kim SI, Ryu YJ, Lee JH, Chun EM, Chang JH. The body mass index as a prognostic factor of critical care. Korean J Intern Med 2010; 25:162-167.

54. Pieracci FM, Hydo L, Pomp A, Eachempati SR, Shou J, Barie PS. The relationship between body mass index and postoperative mortality from critical illness. Obes Surg. 2008; 18:501-507.

55. Smith RL, Chong TW, Hedrick TL, Hughes MG, Evans HL, McElearney ST, et al. Does body mass index affect infectionrelated outcomes in the intensive care unit? Surg Infect 2007; 8:581-588.

56. Aldawood A, Arabi Y, Dabbagh O. Association of obesity 
with increased mortality in the critically ill patient. Anaesth Intensive Care 2006; 34:629-633.

57. Tremblay A, Bandi V. Impact of body mass index on outcomes following critical care. Chest 2003; 123:1202-1207.

58. Dossett LA, Heffernan D, Lightfoot M, Collier B, Diaz JJ, Sawyer RG, et al. Obesity and pulmonary complications in critically injured adults. Chest. 2008; 134:974-980.

59. Byrnes MC, McDaniel MD, Moore MB, Helmer SD, Smith RS. The effect of obesity on outcomes among injured patients J Trauma 2005; 58: 232-237.

60. Diaz JJ Jr, Norris PR, Cllier BR, Berkes MB, Ozdas A, May $\mathrm{AK}$, et al. Morbid obesity is not a risk factor for mortality in critically ill trauma patients. J Trauma 2009; 66: 226-231.

61. Alban RF, Lyass S, Margulies DR, Shabot MM. Obesity does not affect mortality after trauma. Am Surg 2006; 72: 966969.

62. Brown CV, Neville AL, Rhee P, Salim A, Velmahos GC, Demetriades D. The impact of obesity on the outcomes of 1,153 critically injured blunt trauma patients. J Trauma 2005; 59:1048-1051.

63. Choban PS, Weireter LJ Jr, Maynes C. Obesity and increased mortality in blunt trauma. J Trauma 1991 31: 1253-1257.

64. Neville AL, Brown CVR, Weng J, Demetriades D, Velmahos GC. Obesity is and independent risk factor of mortality in severely injured blunt trauma patients. Arch Surg 2004;139:983-987.

65. Christmas AB, Reynolds J, Wilson AK, Franklin GA, Miller FB, Richardson JD, et al. Morbid obesity impacts mortality in blunt trauma. Am Surg 2007;73:1122-1125.

66. Renes J, Rosenow A, Mariman E. Novel adipocyte features discovered by adipoproteomics. Adipobiology 2009;1:5-14.

67. Motyl KJ, McCabe LR, Schwartz AV. Bone and glucose metabolism: a two-way street. Arch Biochem Biophys 2010; 503:2-10.

68. Yamamoto M, Yamaguchi T, Yamauchi M, Sugimoto T. Low serum level of the endogenous secretory receptor for advanced glycation end products (esRAGE) is a risk factor for prevalent vertebral fractures in dependent of bone mineral density in patients with type 2 diabetes. Diabetes Care 2009; 32:2263-2268.

69. Blain H, Vuillemin A, Guillemin F, Durant R, Hanesse $B$, de Talance N, et al. Serum leptin level is a predictor of bone mineral density in postmenopausal women. J Clin Endocrinol Metab 2002 87:1030-1035.

70. Cornish J, Callon KE, Bava U, Lin C, Naot D, Hill BL, et al. Leptin directly regulates bone cell function in vitro and reduces bone fragility in vivo. J Endocrinol 2002 175:405-415.

71. Thomas T, Gori F, Khosla S, Jensen MD, Burguera B, Riggs
BL. Leptin acts on human marrow stromal cells to enhance differentiation to osteoblasts and to inhibit differentiation to adipocytes. Endocrinology 1999;140:1630-1638.

72. Ornan EM, Ben-Ami M. The role of leptin in bone development and growth. In: Gertler A, editor. Leptin and Leptin Antagonists. Pub Landes Biosciences. 2009; pp 102-109.

73. Ealey KN, Kaludjerovic J, Archer MC, Ward WE. Adiponectin is a negative regulator of bone mineral and bone strength in growing mice. Exp Biol Med 2008 233:15461553.

74. Ackert-Bicknell C, Rossen C. The genetics of PPARG and the skeleton. PPAR Res 2006.

75. Sundvold H, Lien S., Identification of a novel peroxisome proliferator-activated receptor (PPAR) $\gamma$ promoter in man and transactivation by the nuclear receptor RORa1. Biochem Biophys Res Commun 2001; 287: 383-390.

76. Meunier R, Aaron J, Edouard E,Vignon, G. Osteoporosis and the replacement of cell populations of the marrow by adipose tissue. A quantitative study of 84 iliac crest biopsies. Clin Related Res 1971; 80: 147-154.

77. Verma S, Rajaratnam JH, Denton J, Hoyland JA, Byers RJ. Adipocytic proportion of bone marrow is inversely related to bone formation in osteoporosis. J Clin Pathol 2002; 55: 693-698.

78. Lecka-Czernik B, Gubrij I, Moerman EJ, Inhibition of Osf2/ Cbfal expression and terminal osteoblast differentiation by PPAR 2 . J Cell Biochem 1999; 74:357-371.

79. Moerman EJ, Teng K, Lipschitz DA, Lecka-Czernik B. Aging activates adipogenic and suppressed osteogenic programs in mesenchymal marrow stroma / stem cells: the role of PPAR- $\gamma 2$ transcription factor and TGF- $\beta /$ BMP signaling pathways. Aging Cell 2004; 3: 379-389.

80. Akune T, Ohba S, Kamekura S, et al. PPAR $\gamma$ insufficiency enhances osteogenesis through osteoblast formation from bone marrow progenitors. J Clin Invest 2004; 113: 846-855.

81. Rosen C, Ackert-Bicknall C, Adamo ML et al,. Congenic mice with low serum IGF-1 have increased body fat, reduced bone mineral density, and an altered osteoblast differentiation program. Bone 2004; 35: 1046-4058.

82. Choi JH, Banks AS, Estall JL, Kajimura S, Boström P, Laznik $\mathrm{D}$, et al. Anti-diabetic drugs inhibit obesity-linked phosphorylation of PPARgamma by Cdk5. Nature 2010; 466: 451456.

83. Kouidhi S, Jarboui S, Marrakchi R, Clerget Froidevaux MS, Seugnet I, Abid H, et al. Adiponectin expression and metabolic markers in obesity and type 2 diabetes. J Endocrinol Invest 2010 Jul 22 (in print).

84. Kawai M, Rosen CJ. PPARgamma: a circadian transcription 
factor in adipogenesis and osteogenesis. Nat Rev Endocrinol 2010 Sep 7 (in print).

85. Das UN. Is obesity an inflammatory condition? Nutrition 2001; 17: 953-966.

86. Rextrode KM, Pradhan A, Manson JE, Buring JE, and Ridker PM. Relationship of total and abdominal adiposity with CRP and IL-6 in women. Ann Epidemiol 2003; 13: 674-682.

87. Fontana L. Neuroendocrine factors in the regulation of inflammation: excessive adiposity and calorie restriction. Exp Gerontol 2009; 44: 41-45.

88. Ota N, Nakajima T, Nakazawa I, Suzuki T, Hosoi T, Orimo $\mathrm{H}$, et al. A nucleotide variant in the promoter region of the interleukin- 6 gene associated with decreased bone mineral density. J Hum Genet 2001;46:267-272.

89. Finck BN, Kelley KW, Dantzer R, Johnson RW. In vivo and in vitro evidence for the involvement of tumor necrosis factor- $\alpha$ in the induction of leptin by lipopolysaccharide. Endocrinology 1998;139:2278-2283.

90. Dandona P, Weinstock R, Thusu K, Abdel-Rahman E, Aljada A,Wadden T. Tumor necrosis factor- $\alpha$ in sera of obese patients: fall with weight loss. J Clin Endocronol Metab 83: 2907-2910.

91. Pachler C, Ikeoka D, Plank J, Weinhandl H, Suppan M, Made JK, et al. Subcutaneous adipose tissue exerts proinflammatory cytokines after minimal trauma in humans. Am J Physiol Endocrinol Metab 2007; 293: E690-696.

92. Svoboda P, Kantorová I, Ochmann J. Dynamics of inter- leukin 1, 2 and 6 and tumour necrosis factor alpha in multiple trauma patients. J Trauma 1994; 36: 336-340.

93. Jastrow KM $3^{\text {rd }}$, Gonzalez EA, McGuire MF, Suliburk JW, Kozar RA, Lyengar S, et al. Early cytokine production risk stratifies trauma patients for multiple organ failure. $\mathrm{J} \mathrm{Am}$ Coll Surg 2009; 209: 320-331.

94. Gletsu N, Lin E, Zhu JL, Khaitan L, Ramshaw BJ, Farmer $\mathrm{PK}$, et al. Increased plasma interleukin 6 concentrations and exaggerated adipose tissue interleukin 6 content in severely obese patients after operative trauma. Surgery 2006 140:5057.

95. Cai B, Deitch EA, Grande D, and Ulloa L. Anti-inflammatory resuscitation improves survival in haemorrhage with trauma. J Trauma 2009 66: 1632-1639.

96. Owecki M, Fat tissue and adiponectin: new players in critical care? Crit Care. 2009;13:174.

97. Ventkatesh B, Hickman I, Nisbet J, Cohen J, Prins J. Changes in serum adiponectin concentrations in critical illness: a preliminary investigation. Crit Care 2009;13:R105.

98. Collier B, Dossett L, Shipman J, Day M, Lawson G, Sawyer $\mathrm{R}$, et al. Visceral adiposity is not associated with inflammatory markers in trauma patients. J Trauma 2010; 68: 57-61.

99. Winfield RD, Delano MJ, Dixon DJ, Schierding WS, Cendan JC, Lottenberg L, et al. Differences in outcome between obese and nonobese patients following severe blunt trauma are not consistent with an early inflammatory genomic response. Crit Care Med 2010; 38: 51-58. 